\title{
ANALISA PENGETAHUAN PERAWAT MENGENAI PENERAPAN DOKUMENTASI TERINTEGRASI DI RUMAH SAKIT UNIVERSITAS TANJUNGPURA
}

\author{
Rizki Nurhafizah*, Maria Fudji Hastuti**, Suhaimi Fauzan**** \\ *Mahasiswa Program Studi Keperawatan Universitas Tanjungpura, **Dosen \\ Program Studi Keperawatan Universitas Tanjungpura, ***Dosen Program Studi \\ Keperawatan Universitas Tanjungpura \\ rizkinurhafizah@student.untan.ac.id
}

\begin{abstract}
ABSTRAK
Latar Belakang: Dokumentasi terintegrasi merupakan salah satu standar akreditasi. Sehingga diharapkan dokumentasi terintegrasi diterapkan di seluruh Rumah Sakit selain itu agar perawat terbiasa mengisi lembar dokumentasi terintegrasi antar disiplin ilmu. Untuk itu perlu diketahui pengetahuan perawat mengenai dokumentasi terintegrasi.

Tujuan: Untuk menganalisa pengetahuan perawat mengenai dokumentasi terintegrasi

Metode: Penelitin deskriptif kuantitatif dengan pendekatan cross sectional pada 52 orang perawat yang menjadi responden yang bekerja di ruang Intensive Care Unit, rawat inap, perinatologi dan bedah. Dengan mengisi kuesioner berjumlah 18 pertanyaan yang tebagi 9 pertanyaan dokumentasi keperawatan dan 9 pertanyaan dokumentasi terintegrasi.

Hasil: berdasarkan hasil analisa di dapat tingkat pengetahuan perawat untuk dokumentasi terintegrasi rata-rata baik sebanyak 29 orang $(55,8 \%)$ dan pengetahuan baik dokumentasi keperawatan sebanyak 33 orang $(63,5 \%)$. Uji statistik dengan uji chi-square tabel $2 \times 2$ antara pengetahuan dokumentasi keperawatan dan dokumentasi terintegrasi di dapat nili $\mathrm{p}=0,132(\mathrm{p}>0.05)$

Kesimpulan: Pengetahun perawat mengenai dokumentasi terintegrasi rata-rata baik. Tidak ada hubungan antara pengetahuan dokumentasi keperawatan dengan pengetahuan dokumentasi terintegrasi
\end{abstract}

Kata kunci: Pengetahuan, dokumentasi terintegrasi, dokumentasi keperawatan 


\title{
ANALYSIS OF NURSE'S KNOWLEDGE ABOUT APPLICATION OF INTEGRATED DOCUMENTATION AT TANJUNGPURA UNIVERSITY HOSPITAL
}

\author{
Rizki Nurhafizah*, Maria Fudji Hastuti**, Suhaimi Fauzan**** \\ *Nursing Student of Nursing Department Tanjungpura University, ** Lecture of \\ Nursing Department Tanjungpura University, *** Lecture of Nursing Department \\ Tanjungpura University \\ rizkinurhafizah@student.untan.ac.id
}

\begin{abstract}
Background: Integrated documentation is one of the accreditation standards. It's expected that integrated documentation is applied throughout the Hospital in addition the nurse used to fill the integrated documentation sheet between disciplines. For that we need to know nurse knowledge about integrated documentation.

Objective: To analyze nurses' knowledge of integrated documentation

Method: Quantitative descriptive research with cross sectional approach on 52 nurses who were respondents who worked in Intensive Care Unit, inpatient, perinatology and surgery. By filling out a questionnaire of 18 questions that divide 9 questions of nursing documentation and 9 integrated documentation questions.

Result: based on the analysis result, the nurse's knowledge level for integrated documentation the average good as much as 29 people (55,8\%) and knowledge level of nursing documentation with good 33 people (63,5\%). The statistical test by chi-square test between nursing documentation knowledge and integrated documentation $p=0,132(p>0.05)$

Conclusion: The nurse's knowledge of well-integrated documentation is good. There is no correlation between nursing documentation and integrated of documentation
\end{abstract}

Keyword: Knowledge, integrated documentation, nursing documentation 


\section{PENDAHULUAN}

Pesatnya perkembangan teknologi dan pengetahuan yang terjadi membuat masyarakat sadar akan kualitas pelayanan rumah sakit sehingga mempengaruhi paradigma dalam pelayanan kesehatan. Paradigma fokus pelayanan kesehatan berubah dari provider menjadi berfokus pada pasien ${ }^{(1)}$. Perubahan fokus pelayanan kesehatan mempengaruhi standar akreditasi rumah sakit. Pelayaanan pasien di rumah sakit melibatkan berbagai profesi kesehatan profesional seperti dokter, perawat, farmasi, ahli gizi, radiografer, dll. Sehingga tenaga kesehatan saling terkait satu sama lain dalam memberikan pelayanan kepada pasien yang menempatkan pasien dan keluarga sebagai pusat dari pemberian pelayanan $^{(2)}$.

Pendekatan patient centered care dalam perawatan telah terbukti untuk meningkatkan status pasien. Pendekatan ini mengandalkan pondasi hubungan antara penyedia layanan dan pasien, peningkatan komunikasi, membina iklim positif, dan mendorong pasien untuk berpartisipasi secara aktif dalam interaksi antar keduanya ${ }^{(3)(4)}$. Perawat sebagai salah satu tenaga kesehatan professional yang memberikan pelayanan keperawatan melalui proses asuhan keperawatan sesuai dengan standar praktik keperawatan. Standar tersebut telah diatur menurut Peraturan Menteri Kesehatan RI nomor HK.02.02/MENKES/148/I/2010 pasal 8 , yang menyebutkan ada 7 standar dalam penyelenggaraan praktik keperawatan yang diantaranya praktik keperawatan dilaksanakan melalui kegiatan berupa pelaksanaan asuhan keperawatan $^{(5)}$. Asuhan keperawatan yang dimaksud meliputi pengkajian, penetapan diagnosa keperawatan, perencanaan, implementasi dan evaluasi keperawatan. Dalam menjalankan asuhan keperawatan kepada pasien semua tindakan maupun respon dari pasien dari pengkajian hingga evaluasi harus didokumentasikan $^{(6)}$.

Dokumentasi adalah setiap penglihatan atau bukti fisik dapat berupa tulisan, foto dan lain-lain, yang telah dilakukan dan dapat dikumpulkan atau dipakai kembali atau semua data otentik yang dapat dibuktikan secara hukum dan dapat dipertanggungjawabkan sesuai dengan aturan dan dapat digunakan untuk melindungi klien ${ }^{(7)}$.

Pendokumentasian mempunyai peranan sangat penting baik dari segi peningkatan mutu kualitas pelayanan, aspek hukum, komunikasi, keuangan, pendidikan, penelitian dan akreditasi ${ }^{(8)}$. Dokumentasi keperawatan adalah catatan asuhan keperawatan yang harus dikerjakan dalam proses keperawatan oleh seorang perawat ${ }^{(9)}$. Dokumentasi keperawatan menjadi penting karena menyangkut aspek legal tindakan keperawatan. Perawat bertanggung jawab dan bertanggung gugat dalam pencatatan asuhan keperawatan yang telah diberikan. Informasi yang dicatat oleh perawat dapat menjadi dasar untuk melindungi perawat dalam mengantasipasi pemberi gugatan. Mengingat pentingnya perlindungan hukum bagi perawat, pencatatan dokumentasi keperawatan menjadi suatu kewajiban yang harus dilakukan oleh perawat ${ }^{(10)}$. Hal ini telah diatur dalam UndangUndang Keperawatan No.38 pasal 37 tahun 2014 yang menyebutkan dalam melaksanakan praktik keperawatan 
perawat

mendokumentasikan

berkewajiban

asuhan

keperawatan sesuai standar. Meskipun

demikian dokumentasi keperawatan, mulai dari pengkajian hingga evaluasi yang mengambarkan kondisi kesehatan pasien secara keseluruhan, pada kenyataanya, kualitas pelaksanaan pendokumentasian asuhan keperawatan masih sangat kurang ${ }^{(11)}$.

Memiliki pengetahuan dan wawasan luas sangatlah penting bagi seorang perawat sebagai modal untuk meningkatkan kualitas keperawatan, agar dapat bersaing dengan profesi perawat lainnya baik di dalam negeri maupun luar negri. Pengelolaan pengetahuan mempengaruhi kinerja dengan mempengaruhi hubungan kerja untuk meningkatkan pembelajaran dan pengambilan keputusan ${ }^{(12)}$. Informasiinformasi tentang dunia kesehatan kini sudah dapat di akses dengan internet yang memudahkan perawat untuk mengetahui dan menambah pengetahuan tentang pelayanan kesehatan. Salah satunya tentang adanya perubahan metode pendokumentasian menjadi dokumentasi terintegrasi. Berdasarkan uraian diatas peneliti tertarik untuk melakukan penelitian mengenai pengetahuan perawat mengenai dokumentasi terintegrasi. Penelitian ini berjudul "analisa pengetahuan perawat mengenai penerapan dokumentasi terintegrasi di Rumah Sakit Universitas Tanjungpura.

\section{METODE PENELITIAN}

Jenis penelitian yang digunakan dalam penelitian ini adalah deskriptif kuantitatif dengan pendekatan cross sectional. Dengan jumlah sampel 52 orang perawat yang bekerja diruang rawat inap, Intensive Care Unit, Perinatologi dan bedah yang didapat melalui purposive random sampling dari 60 orang perawat.

Instrument penelitian dengan menggunakan kuesioner yaitu kuesioner 18 pertanyaan pilihan ganda yang terdiri dari 9 pertanyaan tentang dokumentasi keperawatan dan 9 pertanyaan tentang dokumentasi terintegrasi. Analisa data deskriptif dibagi menjadi dua, yaitu analisa data deskriptif univariat dan bivariat yang dilakukan melalui uji statistik nonparametik yaitu dengan uji Chi-Square tabel $2 \times 2$. Adanya hubungan atau tidak nilai $\mathrm{p}<0.05$, semakin kecil nilai $\mathrm{p}$ dari 0.05 maka dapat dikatakan adanya hubungan. 


\section{HASIL PENELITIAN \\ Analisa Univariat}

Tabel 1.1

Karakteristik Perawat Berdasarkan Usia, Jenis Kelamin di ruang Intensive Care Unit, Rawat inap, Perinatologi dan Bedah Rumah Sakit Universitas Tanjungpura $(n=52)$

\begin{tabular}{llcc}
\hline \multirow{2}{*}{ Karakteristik Responden } & Frekuensi & $(\%)$ \\
\hline \multirow{2}{*}{ Usia } & $\begin{array}{c}\text { a. Remaja akhir } \\
(17-25 \text { th) }\end{array}$ & 28 & 53,8 \\
\cline { 2 - 4 } & $\begin{array}{c}\text { b. Dewasa Awal } \\
(26-35 \text { th) }\end{array}$ & 24 & 46,2 \\
\hline \multirow{2}{*}{ Penis Kelamin } & a. Laki-laki & 6 & 11,5 \\
\cline { 2 - 4 } & b. Perempuan & 46 & 88,5 \\
\hline \multirow{2}{*}{ Pelatihan } & a. D3 & 19 & 36,5 \\
\cline { 2 - 4 } & b. D4 & 2 & 3,8 \\
\hline \multirow{2}{*}{ Pengalaman } & c. S1 & 31 & 59,6 \\
\hline & a. Pernah & 9 & 17,3 \\
\hline & b. Tidak Pernah & 43 & 82,7 \\
\hline & a. $<5$ tahun & 42 & 80.8 \\
\hline & b. 6-10 tahun & 8 & 15.4 \\
\hline Masa Kerja & a. 11 tahun & 2 & 3.8 \\
\hline & b. 3-4 tahun & 34 & 34.6 \\
\hline Total & & 18 & 100 \\
\hline
\end{tabular}

Sumber : Data Primer (2016) Telah Diolah

Karakteristik berdasarkan tabel 1.1 menunjukkan bahwa dari 52 responden di dapatkan hasil usia terbanyak adalah responden dalam rentang usia remaja akhir yaitu 17-25 tahun sebanyak 28 orang $(53,8 \%)$ dan didominasi dengan responden berjenis kelamin perempuan sebanyak 46 orang $(88,5 \%)$. Proporsi terbesar dari tingkat pendidikan terakhir responden yaitu S1 Keperawatan sebanyak 31 orang $(59,6 \%)$. Perawat yang telah mengikuti pelatihan terkait pendokumentasian keperawatan hanya 9 orang $(17,3 \%)$ jumlahnya sangat sedikit jika dibandingkan dengan perawat yang belum pernah mengikuti pelatihan terkait dokumentasi selama responden bekerja di Rumah Sakit Universitas Tanjungpura. Rata-rata responden memiliki pengalaman kurang dari 5 tahun sebanyak 42 orang $(80,8 \%)$. Karena Rumah sakit Universitas Tanjungpura telah berdiri 4 tahun sehingga lama kerja perawat di bagi menjadi 2 yaitu 1-2 tahun dan 3-4 tahun. Perawat yang bekerja di rumah sakit untan memiliki masa kerja terbanyak berjumlah 34 orang $(65.4 \%)$ perawat dengan masa kerja 1-2 tahun. 
Tabel 1.2

Distribusi Tingkat Pengetahuan Perawat Terkait Dokumentasi Keperawatan di ruang Intensive Care Unit, Rawat inap, Perinatologi dan Bedah RS Universitas Tanjupura

\begin{tabular}{lcc}
\hline \multicolumn{1}{c}{ Pengetahuan } & frekuensi & $\%$ \\
\hline Dokumentasi Keperawatan & & \\
Baik & 33 & 63,5 \\
Kurang Baik & 19 & 36,5 \\
\hline Dokumentasi Terintegrasi & & \\
Baik & 29 & 55,8 \\
Kurang Baik & 23 & 44,2 \\
\hline Total & 52 & 100 \\
\hline
\end{tabular}

Sumber : Data Primer (2016) sudah diolah

Hasil analisa pada tabel 1.2 di dapat hasil tingkat pengetahuan perawat terkait dokumentasi keperawatan bahwa rata-rata perawat berpengetahuan baik. Hasil analisa menunjukkan sebanyak 33 orang $(63,5 \%)$ perawat berpengetahuan baik tentang dokumentasi keperawatan dan 19 orang $(36,5 \%)$ berpengetahuan kurang baik. Hasil tingkat pengetahuan terkait dokumentasi terintegrasi rata-rata perawat berpengetahuan baik. Sebanyak 29 orang $(55,8 \%)$ perawat memiliki tingkat pengetahuan baik dan 23 orang $(44,2 \%)$ memiliki tingkat pengetahuan kurang baik mengenai dokumentasi terintegrasi.

\section{Analisa Bivariat}

Tabel 1.3

Analisa hubungan tingkat pengetahuan mengenai dokumentasi keperawatan terhadap tingkat pengetahuan dokumentasi terintegrasi di ruang keperawatan intensive care unit, rawat inap, perinatologi dan bedah di Rumah Sakit Universitas Tanjungpura.

\begin{tabular}{|c|c|c|c|c|c|c|}
\hline \multirow[t]{2}{*}{ Pengetahuan } & & \multicolumn{4}{|c|}{$\begin{array}{l}\text { Dokumentasi } \\
\text { Terintegrasi }\end{array}$} & \multirow[b]{2}{*}{$p$} \\
\hline & & Baik & $\%$ & $\begin{array}{c}\text { Kurang } \\
\text { baik }\end{array}$ & $\%$ & \\
\hline \multirow{2}{*}{$\begin{array}{l}\text { Dokumentasi } \\
\text { Keperawatan }\end{array}$} & Baik & 21 & 40.4 & 12 & 23,1 & \multirow[b]{2}{*}{0,132} \\
\hline & $\begin{array}{c}\text { Kurang } \\
\text { Baik }\end{array}$ & 8 & 15,4 & 11 & 21,1 & \\
\hline Total & & 29 & 65,8 & 23 & 44,2 & \\
\hline
\end{tabular}

Sumber: uji chi square table $2 \times 2$

Berdasarkan tabel 1.3 didapatkan data bahwa yang memiliki pengetahuan dokumentasi keperawatan baik dengan pengetahuan dokumentasi terintegrasi baik sebanyak 21 orang (40.4\%), memiliki pengetahuan dokumentasi keperawatan baik dengan pengetahuan dokumentasi terintegrasi kurang sebanyak 12 orang $\quad(23,1 \%)$, memiliki pengetahuan dokumentasi keperawatan kurang baik dengan pengetahuan dokumentasi terintegrasi baik sebanyak 8 orang $(15,4 \%)$, 
memiliki pengetahuan dokumentasi keperawatan kurang baik dengan pengetahuan dokumentasi terintegrasi kurang baik sebanyak 11 orang $(21,1 \%)$. Berdasarkan uji chi-square dapat disumpulkan bahwa nilai $p$ $(0.132)>0,05$ yang artinya tidak ada hubungan antara pengetahuan dokumentasi keperawatan dengan pengetahuan dokumentasi terintegrasi di ruang perawatan intensive care unit, rawat inap, perinatologi dan bedah di Rumah Sakit Universitas Tanjungpura.

\section{PEMBAHASAN}

\section{Karaktertik Responden}

\section{1) Usia}

Berdasarkan hasil penelitian, responden perawat yang bekerja di Rumah sakit Universitas Tanjungpura ini tergolong masih muda berkisar antara 22-35 tahun dikarenakan Rumah sakit Universitas Tanjungpura masih dalam kategori baru sehingga tidak ada perawat-perawat senior yang bekerja lebih lama. Rentang usia perawat yang masih tergolong muda akan memudahkan perawat dalam menambah pengetahuan dan meningkatkan pengalaman belajarnya sehingga perawat dapat mengaplikasikan tentang pengetahuannya sehingga kinerja perawat semakin baik.

Hal ini sesuai dengan Sutrisno yang menyatakan usia dibawah 30 tahun adalah masa usia paling produktif karena pada usia tersebut seseorang dapat mencapai hasil kerja secara optimal $^{(13)}$. Sejalan dengan penelitian Sunar yang menjelaskan terdapat hubungan yang signifikan antara pengaruh umur dan produktifitas ${ }^{(14)}$.

\section{2) Pendidikan}

Berdasarkan hasil penelitian, responden di dapatkan bahwa pendidikan terbanyak dari responden adalah $\mathrm{S} 1$ keperawatan yang berjumlah 31 orang. Hal ini menujukkan bahwa tingkat pendidikan perawat pelaksana di rumah sakit Untan sebagian besar memiliki tingkat pendidikan yang cukup tinggi. Baroka (2017) menyatakan pendidikan yang dicapai seorang diharapkan menjadi faktor determinan produktifitas antara lain knowledge, skills, abilities, attitude dan behavior, yang cukup dalam menjalankan aktifitas pekerjaannya ${ }^{(15)}$. Faizin menyatakan salah satu faktor yang dapat meningkatkan produktifitas atau kinerja perawat adalah pendidikan formal perawat. Pendidikan memberikan pengetahuan bukan saja yang langsung dengan pelaksanaan tugas, tetapi juga landasan untuk mengembangkan diri serta kemampuan memanfaatkan semua sarana yang ada disekitar kita untuk kelancaran tugas. Semakin tinggi pendidikan semakin tinggi produktivitas kerja $^{(16)}$.

\section{3) Masa Kerja dan Pengalaman}

Berdasarkan hasil penelitian di dapatkan perawat yang memiliki pengalaman kurang dari 5 tahun sebanyak 42 orang dan perawat yang memiliki pengalaman 6-10 tahun sebanyak 8 orang dan perawat yang mempunyai pengalaman lebih dari 11 tahun sebanyak 2 orang. Peneliti 
menyimpulkan sebagian besar perawat yang bekerja di Rumah Sakit Untan masih memiliki sedikit pengalaman. Masa jabatan bila dinyatakan sebagai pengalaman kerja, menjadi sebuah dasar perkiraan yang baik atas produktivitas karyawan ${ }^{(17)}$.

Hal ini sejalan dengan penelitian notoarmodjo, semakin lama bekerja, maka akan semakin banyak pengalaman yang didapat dan semakin banyak kasus yang ditangani sehingga membuat seseorang semakin terampil dan teliti menyelesaikan pekerjaan ${ }^{(18)}$.

\section{4) Pelatihan}

Sebanyak 52 perawat yang menjadi subjek penelitian didapatkan hasil hanya sebagian kecil perawat yang pernah mengikuti pelatihan terkait pendokumentasian yaitu sebanyak 9 orang $(17,3 \%)$. Notoadmojo mengungkapkan bahwa pelatihan merupakan kegiatan yang dapat dilakukan untuk meningkatkan kemampuan seseorang terhadap suatu bidang. Latihan merupakan perbuatan pokok dalam kegiatan belajar yang dapat meningkatkan pengetahuan $^{(19)}$.

Sejalan dengan pernyataan di atas hal yang sama juga dijelaskan Mailool (2017) yang menyatakan pengetahuan yang diperoleh dari pendidikan formal tidaklah cukup, sehingga perlu adanya ilmu atau pengetahuan yang diperoleh lewat pendidikan nonformal, seperti mengikuti pelatihan-pelatihan ataupun berbagai seminar dalam bidang keperawatan agar pengetahuan dalam lingkup keperawatan semakin meningkat ${ }^{(20)}$

5) Tingkat Pengetahuan Terkait Dokumentasi Keperawatan dan Dokumentasi Terintegrasi

Hasil penelitian menunjukkan pengetahuan perawat terkait dokumentasi keperawatan tergolong baik. Pengetahuan perawat terkait dokumentasi keperawatan yang memiliki pengetahuan baik sebanyak 33 orang responden $(63,5 \%)$ dan perawat memiliki pengetahuan kurang baik sebanyak 19 responden $(36,5 \%)$.

Tingkat pengetahuan terkait dokumentasi terintegrasi didapatkan hasil sebanyak 29 responden $(55,8 \%)$ memiliki pengetahuan baik, dan sebanyak 23 orang $(44,2 \%)$ berpengetahuan kurang baik.

Sehingga dapat disimpulkan bahwa responden yang memiliki pengetahuan baik terkait dokumentasi keperawatan dan dokumentasi terintegrasi cenderung lebih banyak dibandingkan dengan yang memiliki pengetahuan yang kurang baik. Sehingga dapat disimpulkan bahwa responden yang memiliki pengetahuan baik terkait dokumentasi keperawatan cendrung lebih banyak dibandingkan dengan yang memiliki pengetahuan yang kurang baik.

Faktor yang mempengaruhi pengetahuan juga sangat beragam, usia memang mencerminkan pengetahuan tetapi kemampuan intelektual juga harus dipertahankan dengan dilatih secara terus menerus agar tetap 
diingat. Hal ini di dukung oleh Sudarmina yang menjelaskan sebuah teori yang menyebutkan bahwa pengetahuan juga didasarkan pada ingatan ${ }^{(21)}$. Menurut Hanifah pengetahuan seseorang juga dipengaruhi beberapa faktor seperti tingkat pendidikan dan pekerjaannya ${ }^{(22)}$.

Sependapat dengan Adi (2004) yang menyatakan bahwa mereka yang berpendidikan lebih tinggi akan memiliki daya tangkap yang lebih baik dalam menangkap pesan yang disampaikan dibandingkan dengan mereka yang rendah pendidikannya ${ }^{(23)}$.

Hal ini sejalan dengan hasil penelitian rizki dwi yang memperlihatkan adanya hubungan yang bermakna antara pendidikan dengan pengetahuan perawat terkait pendokumentasian $^{(10)}$. Hal ini sejalan dengan penelitian yang dilakukan Baroka menunjukan adanya hubungan yang signifikan tingkat pendidikan dengan pengetahuan seseorang ${ }^{(15)}$.

6) Analisa Pengetahuan Terkait Dokumentasi Keperawatan dan Dokumentasi Terintegrasi

Hasil penelitian melalui uji chisquare didapatkan data bahwa perawat yang memiliki pengetahuan baik terkait dokumentasi keperawatan dan dokumentasi terintegrasi sebanyak 21 orang $(40,4 \%)$, perawat yang memiliki pengetahuan baik dokumentasi keperawatan tetapi kurang baik dokumentasi terintegrasi sebanyak 12 orang $(23,1 \%)$, perawat yang memiliki pengetahuan dokumentasi keperawatan kurang dengan pengetahuan baik dokumentasi terintegrasi 8 orang $(15,4 \%)$, perawat yang sama-sama memiliki pengetahuan kurang baik terkait dokumentasi keperawatan dan dokumentasi terintegrasi sebanyak 11 orang $(21,1 \%)$.

Berdasarkan uji ch-square dapat disimpulkan bahwa nilai $\mathrm{p}>0.05$ dengan nilai $\mathrm{p}=0.132$ yang artinya tidak ada hubungan antara tingkat pengetahuan dokumentasi keperawatan dengan tingkat pengetahuan dokumentasi terintegrasi. Hal ini dikarenakan tingkatan pengetahuan harus melalui tahapan proses, seseorang harus terlebih dahulu tahu, kemudian memahami baru dapat mengaplikasikan apa yang ia ketahui. Dalam hal ini dokumentasi keperawatan merupakan rutinitas perawat yang selalu dilakukan sehingga perawat harus tahu dan memahani tata cara dokumentasi keperawatan agar dapat mengaplikasikan dengan baik. Hal ini sesuai dengan teori tingkatan kognitif pengetahuan yaitu : mengetahui, memahami, mengaplikasikan, menganalisa, menyintesis dan mengevaluasi dapat disimpulkan bahwa sebelum seseorang dapat mengaplikasikan pengetahuan yang dimilikinya, seseorang harus dapat mengetahui dan memahami terlebih dahulu tentang suatu hal ${ }^{(24)}$.

Dokumentasi terintegrasi merupakan standar terbaru dalam penilaian akreditasi rumah sakit untuk itu diharapkan setiap 
rumah sakit di seluruh indonesia segera mengaplikasikan lembar dokumentasi terintegrasi. Perawat sebagai salah satu pelaku dokumentasi yang berperan penting dalam merawat dan menyampaikan kondisi pasien kepada disiplin ilmu lain di rumah sakit harus memiliki pengetahuan dan pemahaman tentang dokumentasi terintegrasi agar dapat diaplikasikan dengan baik. Maka dari itu pengetahuan perawat sangat penting untuk selalu dilatih dan dikembangkan agar produktivitas dan kinerja perawat semakin baik, hal ini sejalan dengan Atmanto (2015) menyatakan pengetahuan tentang keperawatan yang dimiliki oleh perawat merupakan modal dasar bagi perawat. Pengetahuan yang dimiliki oleh perawat juga berperan dalam membentuk sikap dan keterampilan sebagai perawat yang dibutuhkan untuk menghasilkan kinerja dan produktivitas yang tinggi ${ }^{(25)}$.

Dokumentasi terintegrasi yang merupakan salah satu pencatatan rekam medis memfasilitasi dan mencerminkan integrasi dan koordinasi keperawatan. Praktisi kesehatan mencatat pengamatan, pengobatan, dan hasil dari diskusi tim perawatan pasien dalam catatan perkembangan dalam bentuk SOAP(IE) pada formulir yang sama di rekam medis, yang diharapkan membantu meningkatkan komunikasi antar professional kesehatan ${ }^{(26)(27)}$.

Hanya dengan berbekal pengetahuan saja belum cukup untuk mengaplikasikan pengetahuan yang dimiliki karena kesadaran seseorang yaitu motivasi juga menjadi faktor penting pengaplikasian dari pengetahuan yang dimiliki. Supervisi dari atasan juga menjadi salah satu cara ekternal agar perawat mau mengaplikasikan pengetahuan yang dimiliki sehingga akan tercipta kinerja perawat yang baik.

\section{PENUTUP \\ Kesimpulan}

Berdasarkan hasil penelitian didapatkan hasil karakteristik responden didominasi usia kurang dari 30 tahun. Perawat didominasi oleh perawat berjenis kelamin wanita sebanyak $88,5 \%$. Pengalaman bekerja sebagai perawat kurang dari 5 tahun sebanyak $80.8 \%$ dan pelatihan terkait pendokumentasian juga baru di ikuti oleh 9 orang perawat. Hasil pengukuran pengetahuan perawat terkait dokumentasi keperawatan ratarata perawat berpengetahuan baik sebanyak $63.5 \%$. Pengetahuan perawat terkait dokumentasi terintegrasi perawat memiliki pengetahuan baik $55.8 \%$. Tidak ada hubungan antara tingkat pengetahuan dokumentasi keperawatan dengan tingkat pengetahuan dokumentasi terintegrasi

\section{Saran}

Secara praktisi diharapkan menjadi bahan masukan bagi Rumah Sakit Sehingga bisa menjadi acuan kebijakan dalam meningkatkam kualitas pelayanan perawatan dalam pendokumentasian. Bagi Perawat penelitian ini diharapkan akan memberikan implikasi dan meningkatkan kompetensi perawat Sehingga perawat menyadari akan 
pentingnya pengetahuan yang dimiliki perawat dalam pelayanan keperawatan dan diharapkan perawat memiliki motivasi untuk menambah wawasan tentang pelayanan keperawatan khususnya dokumentasi terintegrasi jika tidak ada motivasi dari perawat untuk memahami dan kesadaran dari perawat untuk mengembangkan pengetahuannya.

Secara Teoritis hasil penelitian ini diharapkan bisa menambah referensi dalam perkembangan ilmu keperawatan khususnya mengenai pendokumentasian dan pengetahuan perawat. Penelitian ini dapat menjadi masukan bagi peneliti selanjutnya dan dapat memberikan data yang relevan terkait dengan dokumentasi keperawatan dan dokumentasi terintegrasi serta faktor-faktor yang mempengaruhi. Diharapkan penelitian selanjutnya dapat melakukan penelitian lebih lanjut terkait faktor lainnya seperti motivasi dan supervisi, persepsi perawat dan lain-lain.

\section{Daftar Pustaka}

1. Srinivasan, A.V. Managing a Modern Hospital 2 eds New Delhi: SAGE Publication; 2008.

2. Frampton S. Patient Centered Care Improvement Guide: Inc. and Picker Institute; 2008.

3. Steward M. The Impact of Patient Centered Care on Outcomes. PudMed. 2010.

4. Rusmawati. Upaya Meningkatkan Kemampuan Perawatan Dalam Menerapkan Patient Centered Care (PCC) di Rumah Sakit. Tesis.
Semarang: Fakultas Kedokteran; 2016.

5. PerMenKes, inventor; Tentang Izin dan Penyelenggaraan Praktik Perawat.. 2010.

6. Sabarulin. Darmanwansyah. Abdullah.R. Faktor yang Mempengaruhi Kinerja Perawat dalam Mendokumentasikan Asuhan Keperawatan di Rumah Sakit Woodward Palu. Jurnal AKK. 2013;: p. 29-34.

7. Priyanto, Sriyono, Yunita. Inovasi Sistem Pendokumentasian Terintegrasi pada Pelayanan keperawatan Intensif di ICCU RSUPN Dr.Ciptomangunkusumo. Karya Ilmiah. Jakarta:; 2011.

8. Ulum, Muh. Miftahul, Wulandari, Ratna dwi. Faktor yang Mempengaruhi Kepatuhan Pendokumentasian Asuhan Keperawatan Berasarkan Teori Milgram. Jurnal Administrasi Kesehatan Indonesia. 2013; 1(3 JuliAgustus).

9. Tamaka, Ryay Silvana. Hubungan Beban Kerja dengan Pendokumentasian Asuhan Keperawatan di Instalasi Gawat Darurat Medik RSUP. Prof.DR.R.D Kandou Manao. E-Kp. 2015; $3(2$ Mei).

10. Asmaranti, Rizki Dwi. Hubungan Faktor-faktor yang mempengaruhi Pengetahuan Perawat Terhadap Pendokumentasian Keperawatan di RSUP Persahabatan. Skripsi. Depok: 
Fakultas Ilmu Keperawatan; 2012.

11. Ning Wang, David Hailey, Ping yu. Quality of nursing Documentation and approaches to its evoluation ; a mixed-method systematic review. Journal of Advanced Nursing. 2011.

12. Orzano., et all. Family Medicine Practice Performance and Knowledge Management, Health care Management review. Frederick. 2008 Jan/Mar; 33(1): p. 21.

13. Sutrisno, E. Manajemen Sumber Daya Manusia Jakarta: Prenada Media Grop; 2011.

14. Sunar. ejurnal.esaunggul.ac.id. [Online].; 2012. Available from: http://ejurnal.esaunggul.ac.id/index.p hp/Formil/article/viewFile/803/736.

15. Baroka, Siti., Pondaag, Linne.,Hamel, Rivelno. Hubungan Kelelahan Kerja Perawat dengan Pendokumentasian Asuhan Keperawatan di Ruangan IRINA C RSUP Prof.DR. R.D. Kandou Manado.. E-Journal Keperawatan e-Kp. 2017 Februari ; 5

16. Faizin, Ahmad. Berita Ilmu Keperawatan. 2008 September; 1(3): p. 37-142.

17. Robbins, S.P dan Timothy, A.J. Perilaku Organisasi. Edisi 12 Jakarta: Salemba Empat; 2008.

18. Notoatmodjo,S. Promosi Kessehatan Teori dan Aplikasi Jakarta: Rineka Cipta; 2010.
19. Notoatmodjo. Pendidikan dan Perilaku Kesehatan Jakarta: Rineka Cipta; 2003.

20. Mailool, Christian Marcelino., Pondaag Linnie., Lolong, Jill. Hubungan Faktor Personal dengan Kinerja Perawat Pelaksana di Instalasi Rawat Inap RSU Pancaran Kasih GMIM Manado. Universitas Sam Ratulangi. eJournal Keperawatan (eKp). 2017 februari; 5(1).

21. Sudarmina. Pendidikan dan Pembetukan watak yang baik, dalam pendidikan untuk masyarakat Indonesia baru, 70 tahun Prof H.A.R. Tilaar, M. Sc Ed. Jakarta: PT Grasindo; 2002.

22. Hanifah, Maryam. Hubungan Usia dan Tingkatan Pendidikan dengan Pengetahuan Wanita Usia 20-50 tahun tentang Periksa Payudara Sendiri (SADARI). skripsi. Jakarta: Fakultas Kedokteran dan Ilmu Kesehatan; 2010.

23. Adi, R. Metodologi penelitian social dan hukum Jakarta: Granit; 2004.

24. Hariandja, MTE. Manajemen sumber daya manusia; pengadaan, pengembangan, pengkompensasian, dan peningkatan produktivitas pegawai Jakarta: Grasindo ; 2007.

25. Atmanto, Agus. Anlisa Pengetuan Sikap, Pengetahuan, Keterampilan dan Komitmen Organisasi Terhadap Kinerja Perawat di RSUD DR Soehadi Prijonegoro. Tesis. 
Universitas Gadjah Mada; 2015.

26. Frelita,G. Situmorang,TJ. Silitonga DS. Joint Commission International Accreditation Standar for Hospital 4th Ed. Oakbrook Terrace U.S.A: Illinois 60181; 2011.

27. Iyer Patricia,W., Camp Nancy,H. Dokumentasi Keperawatan Suatu Pendekatan Proses Keperawatan Jakarta: EGC; 2004. 